\title{
Anaesthesia Problems in Paediatric Dermatology
}

\author{
Mohd Rizwan Khan ${ }^{1}$ \\ ${ }^{1}$ Department of Dermatology, Dr. Rizwan's Skin, Cosmetic and Laser Clinic, Shahjahanpur, Uttar Pradesh, India.
}

\section{ABSTRACT}

\section{BACKGROUND}

In paediatric patients, while giving anaesthesia, any complication can occur even in hospitals which have sophisticated equipment and an expert anaesthetist. It is necessary to tell the guardians of paediatric patients about complications and risks due to anaesthesia. It is vital to tell about risks while talking to guardian of paediatric patient who is being operated even for a minor process. It is often noted that parents think that procedure is minor, and the anaesthesia is also a low-level type without risks. Dermatologist/paediatrician must stress on the fact that general anaesthesia is a major procedure even though the treatment they are going to perform is a simple one. When we compare children to adults, the response we receive is different in them because of many factors. For paediatric patient it is important to go for pre-anaesthetic assessment thoroughly, making an allowance for some extra needs because of many factors such as body composition, protein binding capability, temperature, cardiac output and liver/kidney which are functionally immature. It is advised to have written policy in categorizing and designating procedures on elective or emergency basis for diagnostic, therapeutic and operative methods for which anaesthesia is required. Children can cause harm to themselves or healthcare personnel by kicking and flailing as they are frightened and impatient; young children are flexible and can squirm out of grip and potentiate risk of injury.

\section{KEY WORDS}

Paediatric Anaesthesia, Paediatric Dermatology, Regional Anaesthesia, Topical Anaesthesia.
Corresponding Author: Dr. Mohd Rizwan Khan

C/o. Dr. Rizwan's Skin, Cosmetic and Laser Clinic, Kachcha Katra, Near City Kart, Shahjahanpur-242001, Uttar Pradesh, India.

E-mail:drkhan777@gmail.com

DOI: $10.14260 / j e m d s / 2019 / 756$

Financial or Other Competing Interests: None.

How to Cite This Article:

Khan MR. Anaesthesia problems in paediatric dermatology. J. Evolution Med. Dent. Sci. 2019;8(46):3492-3498, DOI: $10.14260 /$ jemds/2019/756

Submission 23-07-2019,

Peer Review 31-10-2019,

Acceptance 06-11-2019,

Published 18-11-2019.

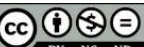




\section{BACKGROUND}

Paediatric patients are of a very vibrant group, because as children grow, they undergo quick changes in physiology that govern the drug nature. Therefore, the use of anaesthesia in paediatric patients warrant special considerations. ${ }^{1,2,3,4}$ For good outcome and complication free operative procedure there is requirement of medical personnel which is qualified and in same approach nowadays equipment are also designed in this manner. Area and zone conditions also play a role in respect to accessibility of expert personnel and availability to amenities. For good patient care concern and while administering general anaesthetic drugs to paediatric group, a clear understanding is required between differences in child and adult physiologic and pharmacologic need. It is necessary to tell Guardian of paediatric patients about complications and risks possibility due to anaesthesia. It is advised to have written policy in categorizing and designating procedures on elective or emergency basis for diagnostic, therapeutic and operative methods for which anaesthesia is required. Patients those are at risks to anaesthesia can be identified with the help of these categories. To maintain proficiency in clinical management it is recommended for medical staff of all faculties to have minimal level of clinical experience in all categories. The staff of patient medical care services is supposed to determine criteria for anaesthetic care for paediatric patients. In paediatric patient anaesthesia, anaesthesiologist must provide and supervised with clinical privileges as noted underneath-

\section{Regular Clinical Privileges}

Anaesthesiologists providing and/or directly supervising clinical care for paediatric patients should be graduates of anaesthesiology residency training programs or its equivalent.

\section{New or Renewed Privileges}

Clinical privileges may be applied for or renewed in the manner determined by the bylaws in compliance with applicable state regulations. In this framework, granting special clinical privileges should be in a manner determined by department of anaesthesiology.

When we apply topically or inject an anaesthetic drug without altering conscious level but achieving temporary loss of sensation and pain stimuli in one part of body is called as Local anaesthesia. These local anaesthetics inhibit the sodium ionic influx in neural fibers for neuron impulse ${ }^{1,2,5}$ When pain stimuli transmission is loss it helps to alleviate fear, to build trust, reduce anxiety and foster relation between doctor and patient. It is an important contemplation in selection of technique to administer local anaesthetic in behaviour of paediatric patient. ${ }^{5,6}$ complications like hematoma, trismus etc., can be minimize by proper placement of anaesthetic agent and having knowledge of gross anatomy and neuroanatomy in paediatric dentistry. One should aware of proper dosage to reduce chance of toxicity and prolonged anaesthesia can lead to accidental lip, tongue or soft tissue trauma ${ }^{5,7}$

Lot of problems being faced by doctors performing procedures on infants and children mentioned in text books, not merely limited to anxiety but pain $\operatorname{control}^{8}$ and poor outcome due to constant or unexpected movement by the children. ${ }^{9}$ Dermatologist who has to perform a procedure on infants or young children knows that they have to face difficulties and incapability of infants to cooperate with the procedure. ${ }^{10}$ In one author's experience terrified and restless children can cause hurt to themselves, parents or healthcare providers by kicking and flailing; young children are flexible and can squirm out of grips and potentiate risk of trauma or injury.

Preterm infant with body weight less than $2 \mathrm{Kg}$ and not completed 37 weeks of gestation is at great risk for anaesthesia and surgery, due to ventilation perfusion mismatch, decrease in lung volume and increase in intrapulmonary shunt because of surfactant concentration is low in these infant. In neonates and preterm infant pre anaesthetic assessment is of great importance, if there is lung volume reduction for any reason, there will be worsening of intra pulmonary shunt. Preterm infants are susceptible to barotrauma and oxygen toxicity.

Body composition, cardiac output distribution, protein binding, temperature of body, functional maturity of kidneys, liver and many more factors an infant and young child respond to anaesthesia differently when compare to adults. ${ }^{11}$ Children have mature renal, hepatic and protein binding functions but in contrast to neonates which have decreased in hepatic renal and protein binding, in addition less part of cardiac output is diverted to kidneys and liver in infants than in older children.

Some factors and changes of body function produces impact on pharmacokinetics of certain medication like there is change in body components i.e. fat, water and muscle with age. Total body water when compare to toddler and term infants is substantially highest in premature infants, because fat and muscle amount increase with age. Pre anaesthetic valuation for a child is important. As matter of fact we rely on the clinical assessment, personal and medical history more and less likely perform any laboratory investigation unless some problem come up from clinical examination.

Topical anaesthesia can reduce pain and are useful for surface procedures like curettage, but risk of absorption may lead to meth-hemoglobinemia, seizure and lack of cooperation by child. ${ }^{11}$ Topical anaesthesia provides only superficial anaesthesia. Infiltrative anaesthesia is required for adequate pain control in addition to topical for many procedures. $^{8,12}$

When we give general anaesthesia that not just mean to make patient unconscious but also to reduce and suppress the perception and physiologic response to noxious stimuli. This can be achieved by producing analgesia, amnesia, akinesia, maintaining electrolyte control, cardiovascular function, IV fluids balance and thermoregulation and vigilance. 12

Chemically local anaesthetic agents are of two types 1 . Esters e.g. benzocaine, procaine, etc and 2. Amides e.g. Prilocaine, lidocaine etc. these local anaesthetics are vasodilators when they are absorbed into circulation, their systemic effect is directly proportion to their plasma level of blood. ${ }^{13}$ Local anaesthetic are added with vasoconstrictors to reduce their rate of absorption in blood as vasoconstrictor agent e.g. Epinephrine and nor-epinephrine constrict blood vessel at injection site. Topical anaesthetics agents are 
available in different forms like gel, ointment, liquid, patch and aerosol. When topical agent is applied it helps to reduce anxiety generated during local anaesthesia injection. Topical anaesthesia is effective up to 2 to $3 \mathrm{~mm}$ deep from skin surface and help to reduce pain of needle penetration. Topical anaesthesia gives superficial anaesthesia only. It can reduce pain and is useful for procedures which are performed on surface like curettage, but absorption of anaesthesia raise risk of meth-hemoglobinemia, seizure in child. ${ }^{11}$ Sometimes infiltrative anaesthesia is required for many procedures for adequate pain control along with topical anaesthesia.8,12

The U.S. Food and Drug Administration (FDA) have warned about the uses of compounded topical anaesthetics and the risk of methemoglobinemia. ${ }^{14,15}$ Best alternative is general anaesthesia as it provides amnesia to operative procedure being performed, associated pain of the procedure and better immobilization. Immobilization provides superior cosmetic outcome, accuracy; reduce risk to patient/guardian and doctors too from unrealistic child. Operating room facility is not always easy for a paediatric dermatologist, so they use surgical centers. In paediatric dermatology general anaesthesia is often used for cosmetic reconstruction and excision of larger lesions.

Before giving anaesthesia, it is obligatory that all children should go through for pre-anaesthetic assessment that comprise of history, documentation of medical allergies and physical examination of airway, lungs and cardiac function. Following we should acquire family history for drug allergy, reaction during anaesthesia, post-surgical hyperthermia and sudden death, questions should be asked about complications if any child in family previously has received general anaesthesia. Lastly in assessment preoperative fasting guidelines should be recommended and every clinician should ensure this.

Prilocaine is available in both form injectable form and topically in combination with lidocaine. Benzocaine is available is liquid, spray and gel forms it is most commonly use topical anaesthetic and available in up to 20 percent concentration. Benzocaine has rapid onset and reaction have been rarely reported also available in array of forms over the counter. $^{16}$ Localized allergic reaction can occur after prolonged and repeated use. ${ }^{17}$ Lidocaine is available in as ointment, spray topical solution indifferent concentration. Topical lidocaine has low incidence of allergic reaction but when absorbed systemically overdose risk increases when combine with injected amide. ${ }^{18}$

It is important to note that the FDA stated that "reliable with animal studies, current human proceedings suggest that a solo comparatively small contact, to general anaesthetic and sedation drugs in children is dubious to have a negative effect." There are risks associated with general anaesthesia; if it was that simple then most children would be agreed with general anaesthesia. However, parents or guardian often will do what they can do avoid jeopardy and may therefore stay away from general anaesthesia. A retrospective review of 226 children receiving 681 procedures at a single institution acknowledged lower rates of complication ${ }^{10}$

General anaesthesia is not completely inevitable in complex diseases. Regardless of the risks, the advantage of general anaesthesia is used in the major neonatal correction such as cleft palate in an infant but not for a treatment of wart or mole removal. When procedures are ancillary then general anaesthesia can be avoided; a combination of topical and local infiltration of anaesthesia can help out.

Impending risks of anaesthesia on neurocognitive development in infants and young children; this is a new debate which is recently has come ahead concerns on the topic of the cataloguing changes of anaesthetic and sedation drugs by US Food and Drug Administration (FDA) in December 2016 specifically paying awareness on the risks in children younger than three years with lengthened $(>3$ hours) and frequent exposures; however this class of contact is implausible with regular dermatologic paediatric procedures. ${ }^{11,12,19 \text {, }}$

In the American academy of dermatology guidelines on in-office anaesthesia, Kouba et al states. ${ }^{20}$ "It is recommended that for patch up of dermal laceration and for minor derma procedures like curettage, first line of scheme of anaesthesia is topical anaesthesia. Topical anaesthesia before infiltrative anaesthesia should be considered for skin biopsy and excision procedures. Only topical anaesthesia is not sufficient in these types of procedures".

Evidence from animal study coerce that contact to all anaesthetic agents in medical use induces neurotoxicity and long term adverse neurobehavioral deficit; however, weather this outcome are suitable to human infants is unidentified. ${ }^{20,21,22}$

Malamed's handbook of local Anaesthesia, $6^{\text {th }}$ edition recommend maximum dosage of $7 \mathrm{mg} / \mathrm{kg}$. Total dosage should be based on child's weight and should never exceed maximum dosage. Lidocaine without epinephrine is no longer available in dental cartridges in North America. ${ }^{23}$ Compounded topical anaesthetics also are available. ${ }^{2,24}$ Two of the common formulation which are available contains lidocaine, tetracaine and phenylephrine in $20 \%, 4 \%, 2 \%$ respectively and lidocaine, prilocaine, tetracaine and phenylephrine in $10 \%, 10 \%, 4 \%, 2 \%$ respectively. $24,25,26$ In orthodontic procedures like gingival contouring and in placement of mini screw implants, as well as to anaesthetize palatal tissues in paediatric dentistry prior to injection or loose tooth extraction without the need for an injection, compounded topical anaesthetics are being used. this compounded topical anaesthesia contains high doses of both amide and ester agent and are at threat for side effects comparable to that of other topical anaesthetics. . $^{214-16,24-26}$ The FDA does not standardize compounded topical anaesthetics and issued admonition about their use. ${ }^{18,24}$

\section{Problems Related to Local Anaesthesia}

Local anaesthetic source biphasic reaction (Excitation followed by depression) in nervous system (CNS). Adverse drug reaction can develop either within 10 minutes or during the injection. ${ }^{16}$ High blood level of local anaesthetic overdose can happen by intravenous injection or repeated injections. ${ }^{5}$ Symptoms and subjective signs of central nervous system toxicity are anxiety, dizziness, confusion, diplopia, drowsiness, tinnitus, tingling and circum-oral numbness. Visible sign such as: muscle twitching, talkativeness, tremor, slow speech, shivering and seizures. Also, sometimes unconsciousness and respiratory arrest may happen. ${ }^{27}$

Local anaesthetics cause biphasic reaction (Stimulation followed by depression) in cardiovascular system (CVS). Primarily heart rate and blood pressure may rise as increase in plasma level of anaesthetic drug there is vasodilatation 
followed by decrease in blood pressure because of depression of myocardium leads to bradycardia and cardiac arrest. Until there is considerably prominent level of local anaesthetic in blood cardio-depressant effects are not seen. ${ }^{23}$

To avert toxicity of local anaesthetic things which are requisite are cautious injection technique, observant examination of the patient and calculation of maximum dose which is based on weight of the patient. Before each injection practitioner should aspirate then inject gradually. ${ }^{23}$ for efficient management before time recognition of a noxious response is critical. Doctor or assistant should stay with the patient after injection till anaesthetic drug commence to take its result. anaesthetic drug administration should be terminated as soon as signs and symptoms of toxicity are seen. Emergency management is based on sternness of the response.2,23

Most allergic response are due to discriminating capability of patient to react to very small dose rather dose related. There are many ways in which allergies can present likewise urticaria, fever, photosensitivity, dermatitis, angiooedema and anaphylaxis. ${ }^{17,23}$ Emergency management is based on pace and sternness of the allergic response.

When anaesthesia duration extend beyond the expected time is called Paraesthesia. This can consequence from trauma to nerve that could be through needle during injection and can also be cause by haemorrhage in or in the region of the nerve. When any nerve is affected then in the involved distribution of that nerve area patient feels like an electric shock. Permanent paraesthesia risk has been estimated to $1: 1,200,000$ for $0.5 \%, 2 \%$ and $3 \%$ local anaesthetics and $1: 500,000$ for $4 \%$ local anaesthetic. ${ }^{28}$ paraesthesia is more frequent with the use of articaine and prilocaine.

No confirmation of abnormal neurocognitive effects with a single concise exposure before 3 years of age or during infancy in otherwise healthy children, ${ }^{29,30}$ reported by two recent clinical studies-

1. The GAS (General Anaesthesia Compared to Spinal Anaesthesia) trial ${ }^{22}$

2. The PANDA (Paediatric Anaesthesia and Neurodevelopment Assessment). ${ }^{20}$

The FDA force that "procedures or surgeries in kids younger than 3 years should not be deferred or avoided when medically essential. ${ }^{30}$ " Most of the studies in human showing adverse outcomes have been retrospective observational studies subject to multiple sources of bias.

Studies and information existing suggests that adverse outcome of anaesthesia to neonates are at higher risk than older infants and same way older infants are at higher risk in compare to children older than 2 years of age. ${ }^{31-36}$ it is being suggested that additional differentiation for paediatric age groups older than 2 years is required, because of differences in anatomic, physiologic and psychological function in children and adults. Recommended age categories are 0 to 1 month, 1 to 6 months, 6 months to 2 years and older than 2 year.

Oxygen is important for life, this we all know, but we have to bear in the mind that it is a medical gas, a drug and it has its own side effects. It is used to prevent hypoxia, to achieve this oxygen concentration in the anaesthesia machine must be as lowest level to stay accustomed with good haemoglobin saturation. Elevated oxygen concentration dilutes the nitrogen content of the lung and can endorse absorption atelectasis ${ }^{37}$ and due to high flow of dry oxygen, mucociliary transport and clearance of secretion decreases. ${ }^{38}$ lot of radicals production is augmented by oxygen like hydrogen peroxide, hydroxyl, singlet oxygen and superoxide anion, which are noxious to proteins and lipids in biological cell membranes. When premature baby got exposure to excess oxygen it may cause eye injury such as retrolental fibroplasia. Oxygen-enriched atmosphere also constitute a fire hazard. ${ }^{38}$

Myocardium function can be diminished to deepen the effect of anaesthesia by the action of inhalation anaesthetic agents so always we have to add opioids without relying only on volatile anaesthetics. Regional methods likewise caudal block and inguinal block in this outlook can also be significant. Recent studies suggest that inhalation anaesthetics have shielding effects alongside ischemiareperfusion injury and these effects may cause clinically relevant improved organ function. ${ }^{39}$ neuromuscular blocking anaesthetic agents are most useful drugs but post anaesthetic morbidity associated due to incomplete reversal of neuromuscular blockers is quite frequently noted.

Efficient and safe anaesthetic procedure used nowadays is total intravenous anaesthesia (TIVA) that can also secure spontaneous ventilation. It is used to supervise anaesthesia for foreign body removal from airway in paediatric patients and numerous surgical procedures. Hazard of malignant hyperthermia which is caused by halogenated anaesthetics can be dodged by use of total intravenous anaesthesia (TIVA).

A new field which is potentially growing is regional anaesthesia for paediatric patients in orientation for ultrasound techniques. Most commonly used regional block is epidural caudal block, it is a easy procedure. With the use of latest local anaesthetics risk of cardiotoxicity and neurotoxicity can be reduce like ropivacaine and levobupivacaine. Recently a very interesting technique i.e. ultrasound trans versus abdominus plane (TAP) block is used nowadays for paediatric patients together with ultrasound peripheral nerve block within assistance single shot and continuous local anaesthetic infusion. .0,41 $^{4}$

Nowadays in operation rooms allergic reactions are very rare. Mostly latex allergies can occur but this can also be prevented by using fewer latex containing items or latex free equipment. This can also be prevented by inquiring any latex allergy during pre-anaesthetic examination.

Dewatcher et al, cited The Ring and Messmer clinical severity scale, distinguishes following reaction levels into four grades- Grade 1. Muco-cutaneous signs: urticaria, erythema with or without angioedema. Grade 2. Mucocutaneous signs with or without hypotension, tachycardia, dyspnoea, gastrointestinal disturbances. Grade 3. Mucocutaneous signs, gastrointestinal disturbances and Lifethreatening signs like cardiovascular-collapse, tachycardia / bradycardia / dysrhythmia, bronchospasm. Grade 4. Cardiac arrest.

Complication can also happen from mechanical ventilation; this is due to pulmonary baro-trauma and volume trauma. According to Curley et al. ${ }^{42}$ "Inflammatory response in the lung can be triggered by mechanical ventilation at clinically significant low tidal volume and for moderately short period of time." If inflammatory response is commenced by low stretch mechanical ventilation, it is 
obligatory particularly in newborns and infants to avoid barotrauma or volume trauma of any variety in the lungs.

I.V. fluids are important therapy which is a part of hard work to maintain volume during anaesthesia and avoid hypovolemia. Infant can urinate excess fluid administered but not capable to generate water if permeate an insufficient amount of I.V. fluids. It is recommended to administer reasonable amount of I.V. fluids in children with nonexistence of problems such as heart disease with retention of fluids. Hemodynamic monitoring and use of techniques that is less invasive are required like trans-oesophageal Doppler and is entirely non-invasive. Parameter which are monitored for hemodynamic stability are cardiac output, peak velocity, stroke volume, corrected flow time, indexed cardiac output and indexed stroke volume may be evaluated during procedures for measurement for fluid loss. To reduce the risk this method allows us to correctly evaluate blood loss throughout an invasive procedure. For neonates and infants paediatric CardioQ may also apply.

Tracheal intubation is not always requisite during minor surgery but often rendering child for airway irritation and laryngospasm threat. In case of imperative bleeding and nonfasting patients, laryngeal airway mask should be avoided.

Coming out from general anaesthesia can be a frightening moment. Intra operative recall of Child should not be willingly dismissed but concentrate on with appropriate follow up. Before disconnecting child from mechanical ventilator, we have to be certain that the patient has regained a normocapnic state without exciting child with suction or other stuff, wait till spontaneous ventilation returns, then neostigmine can be injected in little augmentation and if bradycardia develops atropine can be added. When child is fully awake, open eyes and make actions purposefully then endotracheal tube can be removed. Lighter level of anaesthesia is used for endoscopic procedure as there is no painful stimulus. Long term stress and effects of intra operative responsiveness is remarkably rare but possible. 43

\section{Problems Related to Anaesthesia}

Lot of disorder can be mistakenly related to anaesthesia. Dilated cardiomyopathies are quite commonly seen in paediatric age group and represent a heterogenous group of myocardial problems that results in dilated ventricle and impair systolic function ${ }^{44}$ and can lead to torsade-de-pointes, ventricular tachycardia and ventricular fibrillation.

Hypertrophic cardiomyopathy is represented by hypertrophy of left ventricle, diastolic dysfunction, left ventricle outflow obstruction and sudden cardiac death in some cases in young and healthy patients. ${ }^{44}$

Right ventricle arrhythmogenic dysplasia is a genetic disorder described by right ventricle replacement by a fatty fibrous tissue, ${ }^{44}$ which influence patient to ventricular arrhythmias and right ventricle dysfunction.

Myocarditis can produce from 1) Infections from bacteria, fungi, parasites; 2) Viral infections; 3) Autoimmune disorders; 4) Hypersensitivity reactions; 5) Drugs induced; characterized by myocardium inflammation, with necrosis and degeneration of myocytes. ${ }^{45,46}$

Recent studies by Aleksic et al in serbia ${ }^{47}$ on paediatric anaesthesia complications highlight that anaesthesia complication in children increased in case 1) Paediatric anaesthetist doesn't administered anaesthesia 2) Anaesthesia is given by resident supervised by anaesthesiologist who is occupied at same time with other case.

Sudden infant death syndrome, death of a child unpredicted by history and satisfactory case of death could not be elucidated via comprehensive post-mortem it is called as sudden infant death syndrome. ${ }^{48}$ Peak incidence of the syndrome mostly seen at 2-4 month of age. Mostly cause is unknown. Predisposing factor that produces impetuous a toxic response and lethal cytokine cascade are inherited disorder of fatty acid oxidation, genetic cardiac channelopathies and trivial infection. 48

Sanders and Davidson from Australia ${ }^{49}$ allude to various experimental works in newborn animals, quoted the problem of neurotoxicity possibly anaesthetic induced in neonates. Their results are "as we don't know how poor outcome is associated with developing brain pain possibly due to neurotoxic effect, so it is not wise to reduce dose of anaesthetics or analgesic agent in fright of toxicity, it is rather advisable to delay those procedures that are not crucial and vital, that demands general anaesthesia. We cannot provide any firm recommendation on how long surgery should be delayed as we are uncertain of age when revelation is relevant."

Perouanski and Hemmings state "anaesthetics provide reasonable biochemical substrates in number of tissues for hard-wearing long term effects in inadequately unspoken means via protein synthesis, gene expression, protein processing and cellular function." 50 they accept that it is extremely difficult to study in human subjects but they believe that general anaesthesia generate alterations in functions of central nervous system.

Before closing this article want to bear in addition to entire above mentioned problems, have to learn by heart that many possible complications could arise that mark around the loss of sleep, tiredness and exhaustion of the anaesthesiologist. ${ }^{51}$ Recent studies shows that work presentation after 16 hours of sleeplessness is equivalent to blood alcohol level of $0.1 \%$. It is advice for individual physician to consider in mind about sleep, impairment, fatigue, exhaustion and injury compare to alcohol damage.

\section{CONCLUSIONS}

In comparison to adults, infants and young children respond differently to anaesthesia medications due to many factors including body composition, protein binding, body temperature, distribution of cardiac output, and functional maturity of the liver and kidneys. It is important, to inform parents of the possibility of complications and anaesthetic risks even if it is going to be a minor procedure. There are risks associated with general anaesthesia; if it was that simple then most parents would agree for general anaesthesia. Terrified and restless children can cause hurt to themselves, parents or healthcare providers by kicking and flailing; young children are flexible and can squirm out of grips and are at potential risk of trauma or injury. It is necessary to tell the guardian of paediatric patients about complications and risk possibility due to anaesthesia even though procedure which the patient is undergoing is minor one. General anaesthesia is always associated with risks. Preanaesthetic assessment is of great importance for paediatric patients, particularly in neonatal and preterm infants. 
Anaesthesia for paediatric patients may be provided and supervised by an anaesthesiologist. Making an allowance for special clinical needs of paediatric surgical patients, patientcare facilities are advised to authorize written policies for the purpose of designating and categorizing the types of paediatric operative, diagnostic and therapeutic procedures requiring anaesthesia on elective and emergent bases.

\section{REFERENCES}

[1] Becker DE, Reed KL. Essentials of local anaesthetic pharmacology. anaesth Prog 2006;53(3):98-109.

[2] Ogle OE, Mahjoubi G. Local anaesthesia: agents, techniques and complications. Dent Clin North Am 2012;56(1):133-48.

[3] Blaho K, Winbery S, Merigian K. Pharmacological considerations for the paediatric patient. Optom Clin 1996;5(2):61-90.

[4] Koda-Kimble MA, Young LY, Kradjan WA, et al. Applied therapeutics: the clinical use of drugs. $8^{\text {th }}$ edn. Philadelphia, PA: Lippincott Williams and Wilkins 2005.

[5] Malamed SF. Neurophysiology. In: Handbook of Local Anaesthesia. $6^{\text {th }}$ edn. St. Louis, Mo.: Mosby 2013: p. 2-24.

[6] Dean JA, Avery DR, McDonald RE. Local anaesthesia and pain control for the child and adolescent. In: Dentistry for the Child and Adolescent. 9 th $^{\text {th }}$ edn. St. Louis, Mo.: Mosby 2011: p. 241-52.

[7] Malamed SF. anaesthetic considerations in dental special- ties. In: Handbook of Local Anaesthesia. $6^{\text {th }}$ edn. St. Louis, Mo.: Mosby 2013: p. 277-89.

[8] D'Acunto C, Raone B, Neri I, et al. Outpatient paediatric dermatologic surgery: experience in 296 patients. Pediatr Dermatol 2015;32(3):424-6.

[9] Gerwels JW, Bezzant JL, Le Maire L, et al. Oral trans mucosal fentanyl citrarte premedication in patients undergoing outpatient dermatologic procedures. J Dermatol Surg Oncol 1994;20(12):823-6.

[10] Juern AM, Cassidy LD, Lyon VB. More evidence confirming the safety of general anaesthesia in paediatric dermatologic surgery. Pediatr Dermatol 2010;27(4):35560.

[11] Raper J, Alvarado MC, Murphy KL, et al. Multiple anaesthetic exposure in infant Monkeys alters emotional reactivity to an acute stressor. anaesthesiology 2015;123(5):1084-92.

[12] Jevtovic-Todorovic V, Hartman RE, Izumi Y, et al. Early exposure to common anaesthetic agents causes widespread neurodegeneration in the developing rat brain and persistent learning deficits. J Neurosci 2003;23(3):876-82.

[13] Malamed SF. Pharmacology of vasoconstrictors. In: Handbook of Local Anaesthesia. $6^{\text {th }}$ edn. St. Louis, Mo.: Mosby 2013: p. 25-38.

[14] Guidance for FDA staff and industry: Marketed unapproved drugs-Compliance policy guide. Sec 440.100 Marketed new drugs without approved NDAs or ANDAs. U.S. Department for Health and Human Services, Food and Drug Administration, Center for Drug Evaluation and Research (CDER). http://www.fda.gov/ downloads/Drugs/GuidanceComplianceRegulatory
Information/Guidances/ucm070290.pdf". Accessed September 3, 2015.

[15] Life-threatening side effect with the use of skin products containing numbing ingredients for cosmetic procedures. U.S. Food and Drug Administration. FDA public health advisory. http://www.fda.gov/ Drugs/DrugSafety/PostmarketDrugSafetyInformation forPatientsandProviders/ucm054718.htm Accessed September 3, 2015.

[16] Trapp L, Will J. Acquired methemoglobinemia revisited. Dent Clin North Am 2010;54(4):665-75.

[17] Malamed SF. Systemic complications. In: Handbook of Local Anaesthesia. $6^{\text {th }}$ edn. St. Louis, Mo.: Mosby 2013: p. 311-40.

[18] Malamed SF. Additional armamentarium. In: Handbook of Local Anaesthesia. $6^{\text {th }}$ edn. St. Louis, Mo.: Mosby 2013: p. 110-2.

[19] Brambrink AM, Evers AS, Avidan MS, et al. Isofluraneinduced neuroapoptosis in the neonatal rhesus macaque brain. anaesthesiology 2010;112(4):834-41.

[20] Davidson AJ. Anaesthesia and neurotoxicity to the developing brain: the clinical relevance. Paediatric Anaesthesia 2011;21(7):716-21.

[21] Kouba DJ, LoPiccolo MC, Alam M, et al. Guidelines for the use of local anaesthesia in office-based dermatologic surgery. J Am Acad Dermatol 2016;74(6):1201-19.

[22] Davidson AJ, Disma N, de Graaff JC, et al. GAS consortium. Neurodevelopmental outcome at 2 years of age after general anaesthesia and awake regional anaesthesia in infancy (GAS): an international multicentre, randomized controlled trial. Lancet 2016;387(10015):239-50.

[23] Malamed SF. Clinical action of specific agents. In: Handbook of Local Anaesthesia. $6^{\text {th }}$ edn. St. Louis, Mo.: Mosby 2013: p. 52-75.

[24] Graham JW. Profound, needle-free anaesthesia in orthodontics. J Clin Orthod 2006;40(12):723-4.

[25] Kravitz ND. The use of compound topical anaesthetics: a review. J Am Dent Assoc 2007;138(10):1333-9.

[26] Kravitz ND, Kusnoto B, Tsay TP, et al. The use of temporary anchorage devices for molar intrusion. J Am Dent Assoc 2007;138(1):56-64.

[27] Moore PA, Hersh EV. Local anaesthetics: pharmacology and toxicity. Dent Clin North Am 2010;54(4):587-99.

[28] Malamed SF. Local complications. In: Handbook of Local Anaesthesia. $6^{\text {th }}$ edn. St. Louis, Mo.: Mosby 2013: p. 292310.

[29] Sun LS, Li G, Miller TL, et al. Association between a single general anaesthesia exposure before age 36 months and neurocognitive outcomes in later childhood. JAMA 2016;315(21):2312-20.

[30] General anaesthetic and sedation drugs: drug safety communication- new warnings for young children and pregnant women. US Food and Drugs Administration website. $\quad$ https://www.fda.gov/safety/med watch/safetyinformation/ safety alertsforhumanmedical products/ucm533195.htm. Published December 14, 2016. Accessed July 25, 2017.

[31] Rackow H, Salanitre E. Modern concepts in paediatric anaesthesiology. anaesthesiology 1969;30(2):208-34.

[32] Tiret L, Nivoche Y, Hatton F, et al. Complications related to anaesthesia in infants and children. A prospective 
survey of 40240 anaesthetics. $\mathrm{Br} \mathrm{J}$ Anaesthesiol 1988;61(3):263-9.

[33] Olsson GL, Hallen B, Cardiac arrest during anaesthesia: a computerized study in 250543 anaesthetics. Acta Anaesthesiol Scand 1988;32(8):653-64.

[34] Campling EA, Devlin HB, Lunn JN. The Report of the National Confidential Enquiry into Perioperative Deaths (NCEPOD) 1989. London, UK: The Royal College of Surgeons of England, 1990.

[35] Cohen MM, Cameron CB, Duncan PG. Paediatric anaesthesia morbidity and mortality in the perioperative period. anaesth Analg 1990;70(2):160-7.

[36] Morray JP, Geiduschek JM, Caplan RA, et al. A comparison of paediatric and adult anaesthesia closed malpractice claims. anaesthesiology 1993;78(3):461-7.

[37] Spaeth JP, Kurth CD. The extremely premature infant (micropremie). In: Cote CJ, Lerman J, Todres ID, eds. A practice of anaesthesia for infants and children. Philadelphia: Saunders 2009.

[38] Simon BA, Moody EJ, Johns RA. Therapeutic gases oxygen, carbon dioxide, nitric oxide and helium. In: Brunton L, Lazo J, Parker K, eds. Goodman and Gilman's, the pharmacological basis of therapeutics. New York: McGraw-Hill Publications 2006.

[39] De Hert SG, Preckel B, Schalack WS. Update on inhalational anaesthetics. Curr Opin Anaesthesiol 2009;22(4):491-5.

[40] Galante D. Ultrasound needle guidance in neonatal and infant caudal anaesthesia. Pediatr anaesth 2008;18(12):1233-4.

[41] Galante D, Meola S, Cinnella G, et al. Regional caudal blockade in a paediatric patient affected by the Joubert syndrome. Acta Anaesthesiol Scand 2009;53(5):693-4.
[42] Curley GF, Kevin LG, Laffey JG. Mechanical ventilation taking its toll on the lung. anaesthesiology 2009;111(4):701-3.

[43] Phelan L, Stargatt R, Davidson AJ. Long-term posttraumatic effect of intraoperative awareness in children. Pediatr anaesth 2009;19(12):1152-6.

[44] Jefferies JL, Denfield SW, Dreyer WJ. Heart failure in infants and children: cardiomyopathy. In: Nichols DG, edr. Rogers' textbook of Paediatric intensive care. Philadelphia: Lippincott Williams \& Wilkins 2008.

[45] Breinholdt JP, Nelson DP, Towbin DP. Heart failure in infants and children: myocarditis. In: Nichols DG, edr. Rogers' textbook of Paediatric intensive care. Philadelphia: Lippincott Williams \& Wilkins 2008.

[46] Cooper LT Jr. Myocarditis. New Engl J Med 2009;360(15):1526-38.

[47] Aleksic V, Radulovic D, Milakovic B, et al. A retrospective analysis of anaesthesiologic complications in paediatric neurosurgery. Pediatr anaesth 2009;19(9):879-86.

[48] Kinney HC, Thach BT. The sudden infant death syndrome. New Engl J Med 2009;361(8):795-805.

[49] Sanders RD, Davidson A. anaesthetic-induced neurotoxicity of the neonate: time for clinical guidelines? Pediatr anaesth 2009;19(12):1141-6.

[50] Perouansky M, Hemmings HC Jr. Neurotoxicity of general anaesthetics: cause for concern? anaesthesiology 2009;111(6):1365-71.

[51] Flynn TC. Sleep and fatigue. In: Lobato E, Gravensteinn N, Kirby RR, eds. Complications in anaesthesiology. Philadelphia: Lippincott Williams \& Wilkins 2008. 